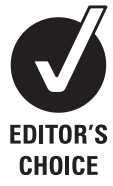

Masonic Cancer Center and Tobacco Use Research Programs, University of Minnesota, Minneapolis, Minnesota, USA ${ }^{2}$ Emergency Response and Air Toxicants Branch, Division of Laboratory Sciences, National Center for Environmental Health, Centers for Disease Control and Prevention, Atlanta, Georgia, USA

\section{Correspondence to} Irina Stepanov, Masonic Cancer Center, University of Minnesota, 420 Delaware Street SE MMC 806, Minneapolis, Minnesota 55455, USA stepa011@umn.edu

Received 30 November 2010 Accepted 19 April 2011 Published Online First 20 May 2011

\title{
Carcinogenic tobacco-specific $N$-nitrosamines in US cigarettes: three decades of remarkable neglect by the tobacco industry
}

\author{
Irina Stepanov, ${ }^{1}$ Aleksandar Knezevich, ${ }^{1}$ Liqin Zhang, ${ }^{2}$ Clifford H Watson, ${ }^{2}$ \\ Dorothy K Hatsukami, ${ }^{1}$ Stephen S Hecht ${ }^{1}$
}

\section{ABSTRACT}

Background Modification of tobacco curing methods and other changes in cigarette manufacturing techniques could substantially reduce the levels of tobacco-specific nitrosamines (TSNA), a group of potent carcinogens, in cigarette smoke. In 1999, two major US cigarette manufacturers stated their intent to move towards using tobaccos low in TSNA. There is no information available on current TSNA levels in tobacco of various cigarettes available in the US, particularly in the newer varieties introduced over the past decade.

Methods Seventeen brands of cigarettes were purchased in April of 2010 from retail stores in Minnesota. TSNA levels were measured in the tobacco filler and smoke of these cigarettes.

Results In all brands, the sum of two potent carcinogenic TSNA - 4-(methylnitrosamino)-1-(3-pyridyl)1-butanone and $N^{\prime}$-nitrosonornicotine - in cigarette filler averaged $2.54( \pm 1.05) \mu \mathrm{g} / \mathrm{g}$ tobacco. This value is virtually identical to the sum of these two carcinogens reported for the tobacco of a US filtered cigarette in 1979. TSNA levels in smoke positively correlated with those in tobacco filler of the same cigarettes.

Conclusion We found no indication that any meaningful attempt was made to reduce or at least control TSNA levels in the new varieties of the popular brands Marlboro and Camel introduced over the last decade. In light of the recently granted regulatory authority to the FDA over tobacco products, regulation of TSNA levels in cigarette tobacco should be strongly considered to reduce the levels of these potent carcinogens in cigarette smoke.

\section{INTRODUCTION}

Among the multitude of tobacco toxicants and carcinogens, tobacco-specific $N$-nitrosamines (TSNAs) are of particular concern due to their abundance and established carcinogenic potency. More than three decades ago, a number of studies conclusively demonstrated that TSNAs were present in relatively high amounts in unburned tobacco and tobacco smoke, and that two of these compounds, 4-(methylnitrosamino)-1-(3-pyridyl)1-butanone (NNK) and $N^{\prime}$-nitrosonornicotine (NNN), are potent carcinogens in laboratory animals. ${ }^{1}$ The accumulated scientific evidence eventually led to the classification of these compounds as human carcinogens by the International Agency for Research on Cancer (IARC). ${ }^{2}$

Studies focused on understanding the sources and mechanisms of TSNA formation in tobacco and cigarette smoke have demonstrated that these compounds are formed during tobacco processing 34 and that TSNA levels in processed tobacco depend on tobacco type and nitrate content. ${ }^{5}$ Formation of additional amounts of TSNA may also occur during burning, ${ }^{6}$ however, the results of studies investigating the relative contribution of pyrosynthesis to the total amount of TSNA found in cigarette smoke have been inconsistent. ${ }^{7}$ Overall, a number of later studies demonstrate that the amounts of TSNA formed during tobacco burning are not significant and that the levels of preformed TSNA in tobacco determine yields in smoke. ${ }^{8-12}$ Thus, the modification of tobacco curing methods and other changes in manufacturing techniques can substantially reduce TSNA levels in cigarette smoke. ${ }^{13}$ The feasibility of implementing such changes is clearly demonstrated by the extremely low TSNA levels in tobacco and smoke of some non-US brands of cigarettes, ${ }^{14}$ and by the reported reductions in TSNA levels in tobacco of Canadian cigarettes that were accompanied by corresponding reductions in smoke deliveries. ${ }^{15}$

In 1999, RJ Reynolds, one of the major US cigarette manufacturers, disclosed that it possesses a 'simple, practical way to dramatically reduce TSNA in flue-cured tobacco', referring to the use of heat exchangers instead of direct-fire burners. ${ }^{16}$ The company stated its intention to begin using lowTSNA tobacco in its cigarette blends 'as soon as they feasibly can'. ${ }^{17}$ Another major US cigarette manufacturer, Philip Morris, reportedly intended to do the same. ${ }^{18}$ Over the following decade, a range of new varieties of popular US cigarette brands were launched by both companies. Philip Morris introduced Marlboro Special Blend in 2001, Marlboro Blend No. 27 in the spring of 2003, Marlboro Smooth Menthol and Marlboro Virginia Blend in 2007, and Marlboro Blend No. 54 in June 2009. Similarly, RJ Reynolds was extending their bestselling brand: Camel No. 9 was launched in 2007 and Camel Crush, which contains a menthol capsule within the filter, was introduced in the summer of 2008. The 'light' version of Camel Crush, called Camel Menthol Silver, appeared on the market in March 2010.

While TSNA levels in the smoke of US cigarettes are reported occasionally, ${ }^{9}{ }^{19}$ the information on TSNA levels in the tobacco filler of various brands of cigarettes currently marketed in the USA is relatively scarce. ${ }^{14}$ In light of the cigarette manufacturers' stated intentions to reduce TSNA levels in cigarette tobacco by modifying tobacco processing techniques, the new varieties that have been recently introduced to the market are of 
particular interest. We analysed a current sample of 17 brands of cigarettes, including some of the varieties launched in the past decade. The filler and the smoke were analysed. To investigate whether cigarette brand and/or filter design affect the transfer rate of TSNA from tobacco to smoke, we also added known amounts of deuterium-labelled NNN and NNK to the filler of each cigarette brand and subsequently analysed the labelled TSNA in the smoke generated by these cigarettes.

\section{MATERIALS AND METHODS Cigarettes}

The cigarettes were purchased in April 2010 from retail stores in Minnesota. One pack of each brand was purchased from three different communities in Minnesota: Golden Valley, St Louis Park and Minneapolis. Full favour varieties of the popular cigarette brands Marlboro, Basic, Camel, Winston, Pall Mall and Doral, as well as the popular mentholated cigarettes Newport Menthol and Kool Filter Kings were selected. ${ }^{20}$ Other samples represented new varieties of Marlboro and Camel introduced in the past decade. All samples were king-size filtered cigarettes packaged in hard packs. The tobacco of cigarettes from each pack was analysed separately, and the mean of three analyses was determined for each brand. The addition of deuterated NNN and NNK to the cigarettes was carried out with a specially designed microsyringe applicator system which uniformly distributed $20 \mu \mathrm{l}$ of spiking solution containing [pyridine- $\mathrm{D}_{4}$ ] NNN and [pyridine- $D_{4}$ ] NNK at a concentration of $10 \mathrm{ng} / \mu \mathrm{l}$ each, along the tobacco rod of the cigarette.

\section{Analyses}

Cigarettes were smoked under US Federal Trade Commission (FTC) standard conditions with a $35-\mathrm{ml}$ puff volume and 2 -s puff duration at a frequency of 1 puff per min, as previously described. ${ }^{9}$ Mainstream smoke was collected on Cambridge filter pads pretreated with ascorbic acid to prevent artefact formation of TSNA. The four commonly reported TSNAs, NNN, NNK, $N^{\prime}$-nitrosoanatabine (NAT) and $N^{\prime}$-nitrosoanabasine (NAB), were analysed as previously described. ${ }^{21}$ Briefly, cigarette filler samples and smoke filter pads were extracted with citrate-phosphate buffer, the extracts were purified on ChemElut cartridges (Varian, Harbor City, California, USA), followed by solid-phase extraction on Sep-Pak Plus silica cartridges (Waters, Milford, Massachusetts, USA). The purified cigarette filler samples were analysed by gas chromatography interfaced with a Thermal Energy Analyser (Orion Research, Beverly, Massachusetts, USA). The smoke samples were analysed by liquid chromatography-tandem mass spectrometry (MS/MS) in positive ion electrospray mode with selected reaction monitoring for $m / z 178 \rightarrow 148$ for $N N N, m / z$ $182 \rightarrow 152$ for [pyridine-D 4 ] NNN, $m / z 208 \rightarrow 178$ for NNK, $m / z$ $212 \rightarrow 182$ for [pyridine-D 4 ]NNK, $m / z 190 \rightarrow 160$ for NAT and $m / z 192 \rightarrow 162$ for NAB. The internal standards 5-methyl$N^{\prime}$-nitrosonornicotine (used for quantitation of NNN, NAT and $\mathrm{NAB}$ ) and 5-(methylnitrosamino)-1-(3-pyridyl)-1-pentanone (used for quantitation of NNK) were monitored at $\mathrm{m} / \mathrm{z} 192 \rightarrow$ 162 and $m / z 222 \rightarrow 192$, respectively. Moisture content was analysed as previously described. ${ }^{22}$

\section{RESULTS}

The results of the TSNA analyses in cigarette filler are summarised in table 1 . The amount of NNN in all brands averaged 1.96 $( \pm 0.92) \mu \mathrm{g} / \mathrm{g}$ tobacco, ranging from $0.33 \mu \mathrm{g} / \mathrm{g}$ tobacco in Marlboro Virginia Blend to $4.03 \mu \mathrm{g} / \mathrm{g}$ tobacco in Marlboro Smooth Menthol. The amount of NNK in the tobacco filler of all brands averaged $0.58( \pm 0.17) \mu \mathrm{g} / \mathrm{g}$ tobacco, ranging from $0.34 \mu \mathrm{g} / \mathrm{g}$ tobacco in Marlboro Virginia Blend to $0.91 \mu \mathrm{g} / \mathrm{g}$ tobacco in Marlboro Blend No. 54. The sum of four TSNAs (referred to as

Table 1 Tobacco-specific $N$-nitrosamines (TSNAs) in the tobacco filler of some US cigarettes marketed in $2010^{*} \dagger$

\begin{tabular}{|c|c|c|c|c|c|c|c|c|}
\hline \multirow[b]{2}{*}{ Cigarette brand } & \multirow[b]{2}{*}{ Filler weight, g } & \multirow[b]{2}{*}{ Moisture content, \% } & \multicolumn{6}{|c|}{ TSNA, $\mu g / g$ tobacco (wet weight) } \\
\hline & & & NNN & NAT & NAB & NNK & NNN + NNK & Total TSNA \\
\hline \multicolumn{9}{|l|}{ Philip Morris (Altria Group, Inc.) } \\
\hline Marlboro Full Flavour & 0.675 & 12.8 & 2.06 & 1.74 & 0.11 & 0.72 & 2.78 & 4.63 \\
\hline Marlboro Special Blend & 0.616 & 12.5 & 2.40 & 1.69 & 0.08 & 0.69 & 3.09 & 4.86 \\
\hline Marlboro Blend No. 27 & 0.627 & 11.3 & 2.44 & 1.77 & 0.10 & 0.62 & 3.06 & 4.93 \\
\hline Marlboro Blend No. 54 & 0.638 & 11.7 & 3.34 & 2.60 & 0.14 & 0.91 & 4.25 & 6.99 \\
\hline Marlboro Smooth Menthol & 0.599 & 9.4 & 4.03 & 2.22 & 0.13 & 0.62 & 4.65 & 7.00 \\
\hline Marlboro Virginia Blend & 0.635 & 11.6 & 0.33 & 0.44 & 0.04 & 0.34 & 0.67 & 1.14 \\
\hline Basic Full Flavour & 0.664 & 11.9 & 2.35 & 1.54 & 0.10 & 0.80 & 3.15 & 4.79 \\
\hline Average for Philip Morris brands & 0.636 & 11.6 & 2.42 & 1.71 & 0.10 & 0.67 & 3.09 & 4.91 \\
\hline SD & 0.026 & 1.1 & 1.15 & 0.67 & 0.03 & 0.18 & 1.28 & 1.96 \\
\hline \multicolumn{9}{|l|}{ Lorillard Tobacco Company } \\
\hline Newport Menthol & 0.664 & 14.1 & 1.75 & 1.29 & 0.08 & 0.49 & 2.24 & 3.62 \\
\hline \multicolumn{9}{|c|}{ RJ Reynolds (Reynolds American, Inc.) } \\
\hline Camel Full Flavour & 0.769 & 13.8 & 1.48 & 1.20 & 0.08 & 0.48 & 1.96 & 3.24 \\
\hline Camel No. 9 & 0.675 & 11.8 & 1.78 & 1.30 & 0.08 & 0.50 & 2.28 & 3.66 \\
\hline Camel No. 9 Menthol & 0.634 & 12.8 & 1.56 & 1.06 & 0.05 & 0.43 & 1.99 & 3.09 \\
\hline Camel Silver & 0.610 & 11.6 & 1.01 & 0.80 & 0.05 & 0.42 & 1.43 & 2.28 \\
\hline Camel Crush & 0.650 & 12.1 & 1.36 & 1.14 & 0.08 & 0.41 & 1.77 & 2.99 \\
\hline Winston Full Flavour & 0.659 & 12.0 & 1.35 & 1.01 & 0.07 & 0.50 & 1.85 & 2.93 \\
\hline Kool Filter Kings & 0.660 & 13.9 & 1.49 & 1.43 & 0.08 & 0.66 & 2.15 & 3.65 \\
\hline Pall Mall Full Flavour & 0.778 & 11.8 & 1.42 & 0.93 & 0.06 & 0.49 & 1.91 & 2.90 \\
\hline Doral Full Flavour & 0.672 & 8.8 & 3.17 & 1.67 & 0.09 & 0.84 & 4.01 & 5.77 \\
\hline Average for RJ Reynolds brands & 0.679 & 12.1 & 1.62 & 1.17 & 0.07 & 0.53 & 2.15 & 3.39 \\
\hline SD & 0.057 & 1.5 & 0.61 & 0.27 & 0.01 & 0.14 & 0.74 & 0.98 \\
\hline
\end{tabular}

*All the cigarette brands analysed here are king-size filtered cigarettes packaged in hard packs.

$\dagger$ Each value is the mean of three analyses.

NAB, $N^{\prime}$-nitrosoanabasine; NAT, $N^{\prime}$-nitrosoanatabine; NNK, 4-(methylnitrosamino)-1-(3-pyridyl)-1-butanone; NNN, $N^{\prime}$-nitrosonornicotine. 
total TSNA) in all brands averaged $4.03( \pm 1.58) \mu \mathrm{g} / \mathrm{g}$ tobacco, ranging from $1.14 \mu \mathrm{g} / \mathrm{g}$ tobacco in Marlboro Virginia Blend to $7.00 \mu \mathrm{g} / \mathrm{g}$ tobacco in Marlboro Smooth Menthol.

All new expansions of the Marlboro brand, except for Marlboro Virginia Blend, had higher levels of total TSNA than the regular Marlboro cigarettes (table 1). Expansions of the Camel brand had total TSNA levels similar to those found in the filler of the regular Camel cigarettes (table 1 ).

The results of the TSNA analyses in cigarette smoke are summarised in table 2. The amount of NNN in all brands averaged $140( \pm 55) \mathrm{ng} /$ cigarette, ranging from $20 \mathrm{ng} /$ cigarette in Marlboro Virginia Blend to $232 \mathrm{ng} /$ cigarette in Marlboro Blend No. 54. The amount of NNK in all brands averaged 75 ( \pm 32$) \mathrm{ng} /$ cigarette, ranging from $26 \mathrm{ng} /$ cigarette in Marlboro Virginia Blend to $134 \mathrm{ng} /$ cigarette in Marlboro Blend No. 54. Total TSNA in all brands averaged $336( \pm 123) \mathrm{ng} /$ cigarette, ranging from $76 \mathrm{ng} /$ cigarette in Marlboro Virginia Blend to $572 \mathrm{ng} /$ cigarette in Marlboro Smooth Menthol.

Overall, with the exception of Marlboro Virginia Blend, Philip Morris cigarettes had relatively higher levels of total TSNA than RJ Reynolds cigarettes: 4.91 ( \pm 1.96 ) compared to 3.39 $( \pm 0.98) \mu \mathrm{g} / \mathrm{g}$ tobacco, respectively in the filler, and 381 ( \pm 157$)$ compared to $301( \pm 92) \mathrm{ng} /$ cigarette, respectively in smoke.

Transfer rate of the deuterated NNN and NNK added to the tobacco filler of the studied cigarettes varied slightly among brands: [pyridine- $\mathrm{D}_{4}$ ] NNN measured in smoke accounted for an average $10.7 \%$ of the amount added to filler (ranging from 7.0 to $13.1 \%$ ), and [pyridine- $\mathrm{D}_{4}$ ] NNK accounted for an average $11.1 \%$ of the amount added to filler (range, $7.4 \%$ to $14.6 \%$ ) (table 2 ).

\section{DISCUSSION}

The carcinogenic potency of the tobacco-specific nitrosamines NNN and NNK is well established, and the existing evidence indicates that these carcinogens can be nearly eliminated from tobacco products. ${ }^{13} 14$ A meaningful effort from the tobacco industry to make the necessary changes in their manufacturing approaches and dramatically reduce TSNA levels in cigarette filler, thus reducing smoke deliveries of these carcinogens, ${ }^{15}$ was anticipated to take place about a decade ago. We here analysed a sample of US cigarettes purchased in the spring of 2010 to examine whether there are any reductions in TSNA levels in the filler and smoke of currently sold brands, including some varieties introduced to the US market over the past decade.

The analytical method used in this study was first described in 1979, when NNN and NNK were quantified in the tobacco of an unidentified commercial filtered US cigarette at $1.4 \mu \mathrm{g} / \mathrm{g}$ tobacco and $0.7 \mu \mathrm{g} / \mathrm{g}$ tobacco, respectively. ${ }^{5}$ If the values reported then are taken as a starting point and compared to those reported for the tobacco of US commercial filtered cigarettes at two 15-year intervals (in $1995^{23}$ and 2010, ie, this report) the conclusion is that despite the available technology to produce cigarettes low in TSNAs, the levels of these carcinogens in the tobacco of popular US cigarette brands have remained essentially the same (figure 1). Similarly, there is no apparent significant reduction in smoke TSNA levels over the past decade: NNN levels in the smoke of 26 brands of cigarettes analysed as a part of the 1999 Massachusetts Benchmark Study ranged from 100 to $317 \mathrm{ng} /$ cigarette, and NNK ranged from 54 to $226 \mathrm{ng} /$ cigarette (summarised in the IARC monograph Tobacco Smoke and Involuntary Smoking ${ }^{24}$ ). Another major observation in our study is that the TSNA levels in the recently introduced new varieties of existing cigarette brands do not reflect any attempt to reduce, or at least control, the levels of these carcinogens. Thus, Marlboro Blend No. 54 contains much higher levels of total TSNA than the regular Marlboro variety: $7.00 \mu \mathrm{g} / \mathrm{g}$ tobacco versus $4.63 \mu \mathrm{g} / \mathrm{g}$ tobacco in the filler, and $572 \mathrm{ng} /$ cigarette versus $378 \mathrm{ng} /$ cigarette

Table 2 Tobacco-specific $N$-nitrosamines (TSNAs) in the smoke of some US cigarettes marketed in $2010^{*} \dagger$

\begin{tabular}{|c|c|c|c|c|c|c|c|c|}
\hline \multirow[b]{2}{*}{ Cigarette brand } & \multicolumn{6}{|c|}{ TSNA，ng/cigarette } & \multicolumn{2}{|c|}{ Percentage transfer from filler to smoke } \\
\hline & NNN & NAT & NAB & NNK & NNN + NNK & Total TSNA & [pyridine- $D_{4}$ ]NNN & [pyridine- $\mathrm{D}_{4}$ ] NNK \\
\hline \multicolumn{9}{|l|}{ Philip Morris (Altria Group, Inc.) } \\
\hline Marlboro full flavour & 171.0 & 119.7 & 16.6 & 90.3 & 261.3 & 397.7 & 11.5 & 9.0 \\
\hline Marlboro special blend & 141.6 & 118.4 & 15.3 & 77.3 & 219.0 & 352.7 & 11.4 & 11.6 \\
\hline Marlboro blend No. 27 & 145.2 & 118.4 & 16.3 & 91.2 & 236.3 & 371.1 & 9.4 & 10.7 \\
\hline Marlboro blend No. 54 & 232.1 & 183.1 & 22.6 & 133.7 & 365.8 & 571.6 & 12.3 & 14.6 \\
\hline Marlboro smooth menthol & 164.2 & 117.1 & 18.1 & 86.4 & 250.6 & 385.7 & 11.1 & 13.7 \\
\hline Marlboro Virginia blend & 19.5 & 27.2 & 3.9 & 25.6 & 45.1 & 76.2 & 10.8 & 8.0 \\
\hline Basic full flavour & 207.1 & 138.7 & 22.6 & 146.1 & 353.1 & 514.4 & 13.0 & 14.0 \\
\hline Average for Philip Morris brands & 154.4 & 117.5 & 16.5 & 92.9 & 247.3 & 381.3 & 11.4 & 11.7 \\
\hline SD & 67.9 & 46.4 & 6.3 & 39.4 & 105.9 & 157.2 & 1.2 & 2.6 \\
\hline \multicolumn{9}{|l|}{ Lorillard Tobacco Company } \\
\hline Newport menthol & 151.8 & 109.3 & 13.6 & 65.6 & 217.3 & 340.3 & 13.1 & 14.6 \\
\hline \multicolumn{9}{|c|}{ RJ Reynolds (Reynolds American, Inc.) } \\
\hline Camel full flavour & 120.2 & 97.8 & 15.6 & 67.5 & 187.7 & 301.1 & 9.5 & 9.2 \\
\hline Camel No. 9 & 102.8 & 77.2 & 12.4 & 44.4 & 147.2 & 236.7 & 9.2 & 9.0 \\
\hline Camel No. 9 menthol & 75.2 & 60.2 & 8.9 & 43.4 & 118.6 & 187.7 & 7.0 & 7.4 \\
\hline Camel silver & 100.3 & 77.6 & 12.4 & 45.6 & 145.9 & 235.9 & 7.9 & 9.0 \\
\hline Camel crush & 96.9 & 90.0 & 15.1 & 48.1 & 145.0 & 250.1 & 9.8 & 12.2 \\
\hline Winston full flavour & 172.8 & 144.4 & 27.9 & 78.5 & 251.3 & 423.7 & 12.0 & 10.4 \\
\hline Kool filter kings & 135.8 & 111.3 & 17.0 & 63.0 & 198.8 & 327.1 & 12.6 & 14.2 \\
\hline Pall mall full flavour & 114.3 & 80.6 & 11.5 & 72.8 & 187.1 & 279.2 & 12.2 & 13.8 \\
\hline Doral full flavour & 225.9 & 124.8 & 15.7 & 100.4 & 326.3 & 466.8 & 8.5 & 7.5 \\
\hline Average for RJ Reynolds brands & 127.1 & 96.0 & 15.2 & 62.6 & 189.8 & 300.9 & 9.8 & 10.3 \\
\hline SD & 46.2 & 26.6 & 5.4 & 19.4 & 64.5 & 91.8 & 2.0 & 2.5 \\
\hline
\end{tabular}

*All the cigarette brands analysed here are king-size filtered cigarettes packaged in hard packs.

tEach value is the mean of two analyses.

NAB, $N^{\prime}$-nitrosoanabasine; NAT, $N^{\prime}$-nitrosoanatabine; NNK, 4-(methylnitrosamino)-1-(3-pyridyl)-1-butanone; NNN, $N^{\prime}$-nitrosonornicotine. 


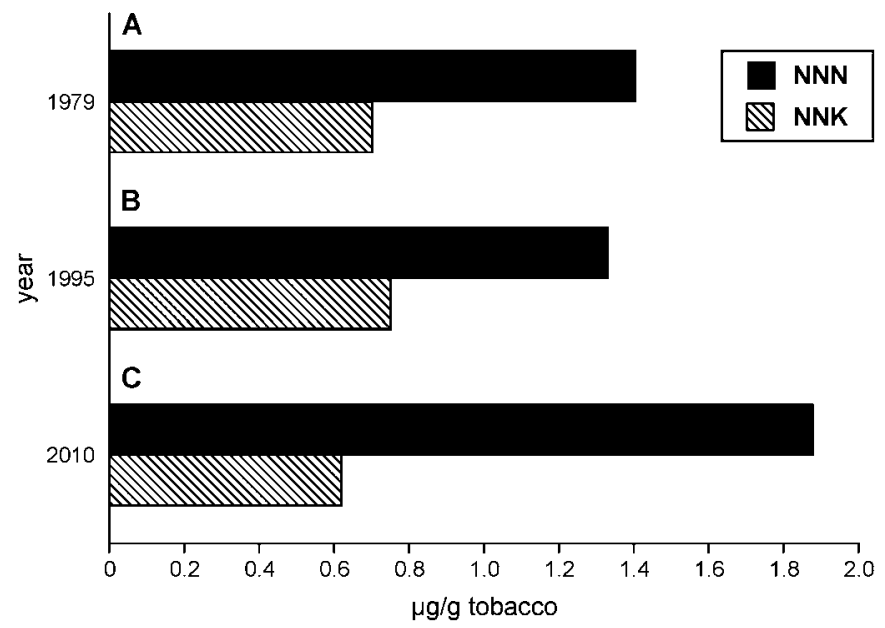

Figure 1 Levels of $N^{\prime}$-nitrosonornicotine (NNN) and 4-(methylnitrosamino)-1-(3-pyridyl)-1-butanone (NNK) in tobacco filler of a US filtered cigarette at three timepoints over a 30 -year period. (A) Levels reported for an unidentified US commercial filtered cigarette. ${ }^{5}$ (B) Average of NNN and NNK levels reported for tobacco filler of five unidentified leading US cigarette brands. ${ }^{23}$ (C) Average levels of NNN and NNK in all brands reported in the current study (table 1).

in smoke (tables 1 and 2). The levels of TSNA in the expansions of the Camel brand are also somewhat similar to the levels in regular Camel cigarettes (tables 1 and 2). The overall slightly lower levels of TSNA in the cigarettes produced by RJ Reynolds, as compared to Philip Morris' brands, could be a consequence of the promised strategy to use low-TSNA flue-cured tobaccos. ${ }^{17}$ However, since flue-cured tobacco comprises only part of a cigarette blend, TSNA reduction in only this type of tobacco leads to not more than a modest change in total TSNA levels. In this respect, Marlboro Virginia Blend cigarettes are an exception. These cigarettes are made from a single type of flue-cured bright tobacco, and as a result, have the lowest NNN and NNK levels among all Philip Morris brands (tables 1 and 2).

We found a positive correlation between TSNA levels in tobacco filler and smoke of the same cigarettes (figure 2), which is consistent with previously published data. ${ }^{9}$ Moreover, the studied brands did not differ drastically in the transfer rate of deuterium-labelled NNN and NNK from cigarette filler to smoke (table 2). These findings indicate that TSNA levels in the smoke of cigarettes investigated here are driven primarily by the corresponding TSNA levels in cigarette filler, once again stressing the importance of changes in tobacco processing and blending approaches for the reduction of smoke deliveries of these carcinogens. As was shown for commercial Canadian and Australian cigarettes, TSNA levels in cigarette smoke can be reduced to just a few nanograms per cigarette, or even virtually eliminated. ${ }^{15} 18$ Thus, the sum of NNN and NNK in the filler of six brands of Canadian cigarettes decreased from an average $1.2 \mu \mathrm{g} / \mathrm{g}$ tobacco in 2003 to an average $0.35 \mu \mathrm{g} / \mathrm{g}$ tobacco in 2005 (71\% reduction). ${ }^{15}$ This resulted in comparable reductions in TSNA levels in the smoke of these cigarettes, and NNN and
Figure 2 Correlation between tobaccospecific nitrosamine levels in tobacco filler and smoke of cigarettes analysed in this study. (A) N'-nitrosonornicotine (NNN). (B) 4-(methylnitrosamino)-1-(3-pyridyl)-1butanone (NNK). (C) Total tobacco-specific $N$-nitrosamines (TSNAs) (sum of NNN, NNK, $N^{\prime}$-nitrosoanatabine (NAT) and $N^{\prime}$-nitrosoanabasine (NAB)).
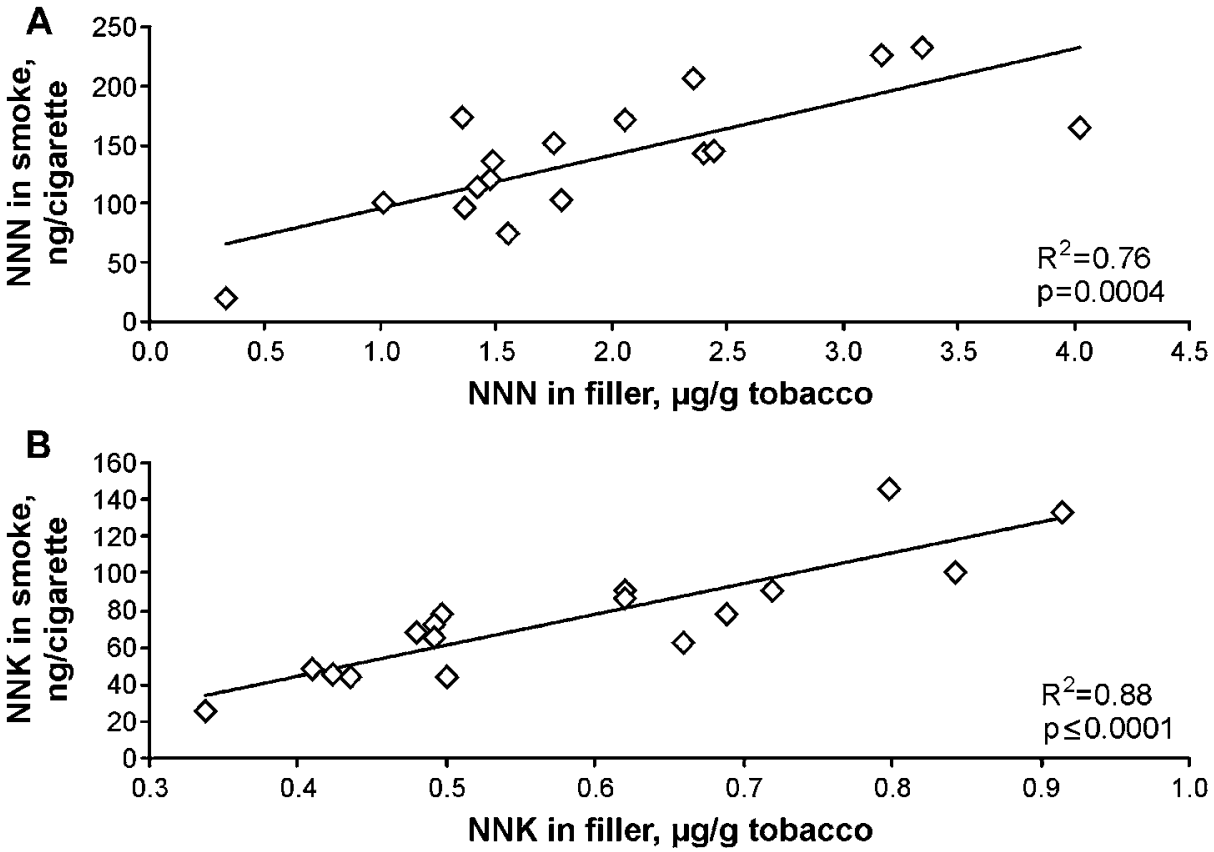

C

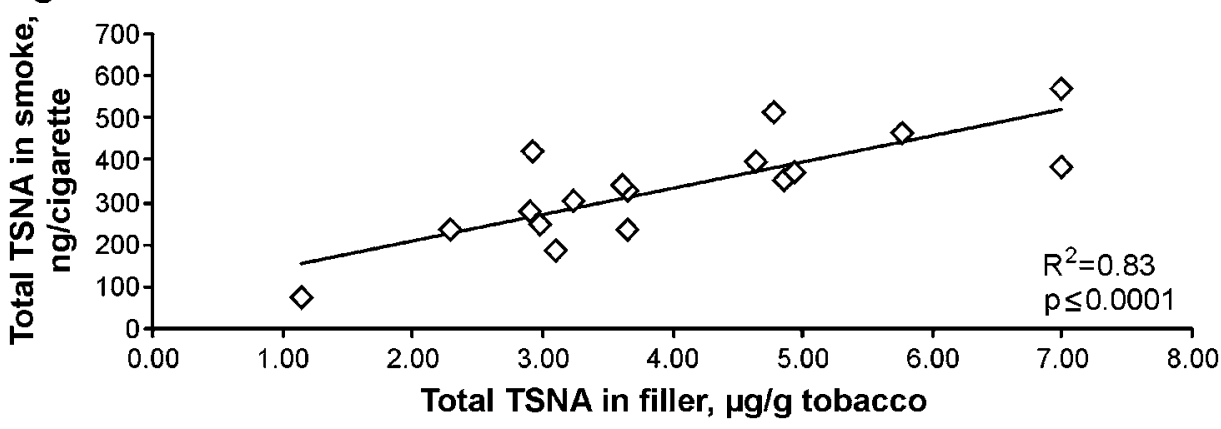




\section{What this paper adds}

Tobacco-specific $N$-nitrosamines (TSNAs), some of which are potent carcinogens, are formed during tobacco processing. The modification of tobacco curing methods and other changes in manufacturing techniques can substantially reduce TSNA levels in tobacco, leading to lower levels of these carcinogens in cigarette smoke.

- This paper demonstrates that despite the available knowledge and tools to reduce TSNA content in cigarette tobacco, the levels of TSNA in the tobacco filler of currently marketed US cigarettes are essentially the same as those reported for a US commercial cigarette 30 years ago.

- TSNA levels in the recently introduced new varieties of existing cigarette brands reflect a remarkable lack of any attempt to reduce, or at least control, the levels of these carcinogens. In light of the recently granted regulatory authority to the US Food and Drug Administration over tobacco products, regulation of TSNA levels in cigarette tobacco should be strongly considered.

NNK levels in cigarettes sold in 2005 averaged as low as $7 \mathrm{ng} /$ cigarette and $11 \mathrm{ng} /$ cigarette, respectively. US cigarette manufacturers possess the necessary knowledge and tools to achieve similar reductions.

TSNAs are not the only carcinogens found in cigarette smoke, and it is unclear whether the reduction of their levels alone will lead to a reduction in risk of developing smoking-induced cancers. However, NNN is the most prevalent oesophageal carcinogen in cigarette smoke, ${ }^{25}$ while the evidence is strong that NNK and polycyclic aromatic hydrocarbons are causative agents for lung cancer in smokers. ${ }^{26}$ Based on its historical levels in cigarette smoke and its ability to induce adenocarcinoma of the lung in three commonly used rodent models, as well as comparative lung cancer death rates from the US and Australia, NNK may be partially responsible for adenocarcinoma becoming the leading type of lung cancer in the USA. ${ }^{27} 28$ Two recent reports demonstrated that higher levels of total 4-(methylnitrosamino)1-(3-pyridyl)-1-butanol (NNAL), a biomarker of NNK exposure in smokers, are associated with a higher risk of lung cancer. ${ }^{29} 30$ Furthermore, a recent study has documented a clear relationship between urinary NNAL levels and mouth-level exposure to TSNA, showing that smokers of low-TSNA cigarettes have lower levels of NNAL in their urine. ${ }^{31}$ Taken together, the results of these studies imply that higher levels of TSNA in cigarette smoke are associated with a higher risk of cancer in smokers.

In summary, despite the available knowledge and tools, there appears to be a remarkable lack of any reduction in the levels of known human carcinogens in products being sold to millions of customers. In light of the recently granted regulatory authority to the US Food and Drug Administration (FDA) over tobacco products, regulation of TSNA levels in cigarette tobacco should be strongly considered.

Funding This study was supported by National Institutes of Health grants P50 DA-13333 as part of the Tobacco Harm Reduction Network and CA-81301.

Competing interests None to declare.

Provenance and peer review Not commissioned; externally peer reviewed.

\section{REFERENCES}

1. Hecht SS, Chen CB, Hoffmann D. Tobacco specific nitrosamines: occurrence, formation, carcinogenicity, and metabolism. Accts Chem Res 1979;12:92-8.
2. International Agency for Research on Cancer. Smokeless tobacco and tobacco-specific nitrosamines. IARC Monographs on the Evaluation of Carcinogenic Risks to Humans. Vol 89. Lyon, FR: IARC, 2007:427-51, 548-53.

3. Hoffmann D, Hecht SS, Ornaf RM, et al. Nitrosonornicotine: presence in tobacco, formation and carcinogenicity. In: Walker EA, Bogovski P, Griciute L, eds. Environmental N-Nitroso Compounds: Analysis and Formation. Lyon, France: International Agency for Research on Cancer, 1976:307-20.

4. Hecht SS, Chen CB, Dong M, et al. Studies on non-volatile nitrosamines in tobacco. Beiträge zur Tabakforschung 1977;9:1-6.

5. Hoffmann D, Adams JD, Brunnemann KD, et al. Assessment of tobacco-specific N-nitrosamines in tobacco products. Cancer Res 1979;39:2505-9.

6. Hoffmann D, Dong M, Hecht SS. Origin in tobacco smoke of $N^{\prime}$-nitrosonornicotine, a tobacco-specific carcinogen: brief communication. J Natl Cancer Inst 1977;58:1841-4.

7. Adams JD, Lee SJ, Vinchkoski N. On the formation of the tobacco-specific carcinogen 4-(methylnitrosamino)-1-(3-pyridyl)-1-butanone during smoking. Cancer Lett 1983;17:339-46.

8. Fischer S, Spiegelhalder B, Eisenbarth J, et al. Investigations on the origin of tobacco-specific nitrosamines in mainstream smoke of cigarettes. Carcinogenesis 1990;11:723-30.

9. Wu W, Zhang $L$, Jain RB, et al. Determination of carcinogenic tobacco-specific nitrosamines in mainstream smoke from U.S.-brand and non-U.S.-brand cigarettes from 14 countries. Nicotine Tob Res 2005;7:443-51.

10. Brunnemann KD, Mitacek EJ, Liu Y, et al. Assessment of major carcinogenic tobacco-specific N-nitrosamines in Thai cigarettes. Cancer Detect Prev 1996;20:114-21

11. Djordjevic MV, Sigountos CW, Brunnemann KD, et al. Formation of 4-(methylnitrosamino)-4-(3-pyridy))butyric acid in vitro and in mainstream cigarette smoke. J Agric Food Chem 1991;39:209-13.

12. International Agency for Research on Cancer. Tobacco Smoke and Involuntary Smoking. IARC Monographs on the Evaluation of Carcinogenic Risks to Humans. Vol 83. Lyon, FR: IARC, 2004:60-7.

13. International Agency for Research on Cancer. Smokeless tobacco and tobaccospecific nitrosamines. IARC Monographs on the Evaluation of Carcinogenic Risks to Humans, v.89. Lyon, FR: IARC, 2007:427-51.

14. Ashley DL, Beeson MD, Johnson DR, et al. Tobacco-specific nitrosamines in tobacco from U.S. brand and non-U.S. brand cigarettes. Nicotine Tob Res 2003;5:323-31.

15. Rickert WS, Joza PJ, Sharifi M, et al. Reductions in the tobacco specific nitrosamine (TSNA) content of tobaccos taken from commercial Canadian cigarettes and corresponding reductions in TSNA deliveries in mainstream smoke from such cigarettes. Regul Toxicol Pharmacol 2008;51:306-10.

16. PR Newswire. Reynolds Tobacco discloses potential method to reduce controversial compounds in flue-cured tobacco, 1999. http://www.thefreelibrary.com (accessed 1999).

17. PR Newswire. Reynolds Tobacco will use flue-cured tobacco low in nitrosamines. Action on Smoking and Health, 1999. http://www.no-smoking.org (accessed 1999).

18. Gray N, Boyle P. The case of the disappearing nitrosamines: a potentially global phenomenon. Tob Control 2004;13:13-16.

19. Richter P, Pechacek T, Swahn M, et al. Reducing levels of toxic chemicals in cigarette smoke: a new Healthy People 2010 objective. Public Health Rep 2008;123:30-8.

20. Maxwell JC. The Maxwell Report: Year End \& Fourth Quarter 2009 Sales Estimates for the Cigarette Industry. Richmond, VA: John C. Maxwell, Jr, 2010.

21. Reynolds American Inc. RAl's 2009 performance highlights underlying strength and resilience. 4 Feb, 2010. www.reynoldsamerican.com/releasedetail.cfm? ReleaselD $=442900$

22. Stepanov I, Jensen J, Hatsukami D, et al. New and traditional smokeless tobacco: comparison of toxicant and carcinogen levels. Nicot Tob Res 2008;10:1773-82.

23. Prokopczyk B, Wu M, Cox JE, et al. Improved methodology for the quantitative assessment of tobacco-specific N-nitrosamines in tobacco by supercritical fluid extraction. J Agric Food Chem 1995;43:916-22.

24. International Agency for Research on Cancer. Tobacco Smoke and Involuntary Smoking. IARC Monographs on the Evaluation of Carcinogenic Risks to Humans vol. 83. Lyon, FR: IARC, 2004:53-119.

25. Hecht SS, Hoffmann D. The relevance of tobacco-specific nitrosamines to human cancer. Cancer Surv 1989;8:273-94.

26. Hecht SS. Tobacco smoke carcinogens and lung cancer. J Nat/ Cancer Inst 1999:91:1194-210.

27. Hecht SS. Biochemistry, biology, and carcinogenicity of tobacco-specific N-nitrosamines. Chem Res Toxicol 1998;11:559-603

28. Burns DM, Anderson CM, Gray N. Do changes in cigarette design influence the rise in adenocarcinoma of the lung? Cancer Causes Control 2011;22:13-22.

29. Yuan JM, Koh WP, Murphy SE, et al. Urinary levels of tobacco-specific nitrosamine metabolites in relation to lung cancer development in two prospective cohorts of cigarette smokers. Cancer Res 2009;69:2990-5.

30. Church TR, Anderson KE, Caporaso NE, et al. A prospectively measured serum biomarker for a tobacco-specific carcinogen and lung cancer in smokers. Cancer Epidemiol Biomarkers Prev 2009;19:260-6.

31. Ashley DL, O'Connor RJ, Bernert JT, et al. Effect of differing levels of tobacco-specific nitrosamines in cigarette smoke on the levels of biomarkers in smokers. Cancer Epidemiol Biomarkers Prev 2010;19:1389-98. 